\title{
Utilização do software scratch para a aprendizagem de lançamentos de projéteis e conceito de gravidade no ensino fundamental
}

Juliana Rodrigues dos Anjos

juliana-anjos@hotmaill,com Canoas, RS, Brasil

\section{Savana dos Anjos Freitas} savanafreitas@hotmail.com Universidade Luterana do Brasil (ULBRA), Canoas, RS, Brasil

\section{Agostinho Serrano de Andrade}

Neto

asandraden@gmail.com Universidade Luterana do Brasil (ULBRA), Canoas, RS, Brasil

\section{RESUMO}

A utilização de softwares e aplicativos no celular tem, cada vez mais, auxiliado em atividades didáticas, tendo em vista a rápida evolução dos recursos tecnológicos, e consequentemente o acesso aos mesmos. Neste trabalho, iremos mostrar como utilizar, de forma combinada, o software Scratch e o jogo Angry Birds Space para uma aprendizagem/ensino de lançamento de projéteis e sobre o conceito de gravidade e, como decorrência, introduzir programação no ensino fundamental. Como, no Brasil, o ensino de Física é predominantemente desenvolvido a partir do ensino médio, o aprendizado de Física no ensino fundamental, acaba ficando abandonado e este trabalho é uma tentativa de discutir atividades que podem ser realizados já neste nível de ensino. O trabalho foi fundamentado em um projeto do PIBID de Física da Universidade Luterana do Brasil.

PALAVRAS-CHAVE: Scratch. Angry Birds Space. Ensino de Física. PIBID. Cinemática. Gravidade. Ensino Fundamental. 


\section{INTRODUÇÃO}

O presente trabalho tem como propósito, descrever como se sucedeu um dos projetos do PIBID de Física, da Universidade Luterana do Brasil. O projeto apresenta a utilização da combinação do software Scratch e um dos jogos da série Angry birds Space ensino/aprendizagem dos conceitos de cinemática, envolvendo tipos de movimentos, velocidade média, ângulos e gravidade, no ensino fundamental.

Hoje em dia, vivemos em um mundo conectado, para onde olhamos, podemos ver uma pessoa utilizando o celular. E essa nova maneira de se viver, também é notável nas escolas. Mediante a isso, buscamos fazer o uso das tecnologias de informação e comunicação como um auxílio para a aprendizagem de lançamentos de projéteis e gravidade.

O Scratch é uma linguagem gráfica de programação, grátis, desenvolvida em dois mil e sete pelo Massachusetts Institute of Technology (MIT) que se constitui como uma linguagem de programação visual e permite ao usuário construir histórias, animações, jogos, simuladores e ambientes visuais de aprendizagem, assim possibilitando ao indivíduo desenvolver o seu pensamento criativo, o raciocínio lógico e sua curiosidade intelectual. A linguagem foi especialmente desenvolvida para o ensino de linguagem de programação à crianças, e foi totalmente traduzida para o português.

Assim como as aplicações relatadas neste trabalho, o uso do Scratch, tem se destacado para as atividades didáticas no Ensino Fundamental, em sala de aula. Despertando o interesse de pesquisadores em ensino (SÁPIRAS; VECCHIA; MALTEMPI, 2015), que buscam testar/validar a contribuição do software para a compreensão do processo de ensino, independente da área de ensino.

Para o atual cenário, onde temos o ensino de física, no nível de Ensino Fundamental, abandonado e novos recursos computacionais, buscamos utilizar as atividades envolvendo simulações e criações no software Scratch, como ambiente de aprendizado para o ensino dos conceitos de Cinemática e programação. Dentro da temática do PIBID, o projeto serve para introduzir aos licenciados rudimentos de modelagem no contexto semelhante ao proposto por Bárbara White (White; Frederiksen, 1998), assim, é possível se apreciar o valor didático da modelagem computacional para o ensino de ciências.

O jogo Angry Birds Space, que foi utilizado como um auxílio para o uso do software Scratch, é um dos últimos lançado da série Angry Birds (Vesterbacka; 2013), que se tornou mundialmente conhecida em poucos anos. O jogo apresenta uma história bem simples, alguns pássaros estão com raiva de porcos verdes que roubaram seus ovos e acabam se escondendo através de diversos materiais, como a madeira, o vidro e concreto, o jogador deverá usar um estilingue para jogar pássaros e assim, podendo atingir os porcos que estão bloqueados por estes materiais. Como foi um grande sucesso, logo em seguida a empresa lançou uma continuidade para a séria como Angry Birds Seasons, Angry Birds Rio, Angry Birds Star Wars I e Il e por último o Angry Birds Space. Este último é o que usamos para desenvolver no projeto, o jogo foi criado em parceria com a NASA (Agencia Espacial Americana), onde tem o mesmo objetivos dos demais, só que com a diferencia que é realizado no espaço, neste jogo, os jogadores deverão saber lidar com a 
gravidade e a atmosfera dos planetas entre outras leis da Física que irão mudar completamente o jogo.

Então, através dessa combinação do Scratch e do Angry Birds Space, aplicamos o projeto no primeiro semestre de dois mil e dezesseis, na E.M.E F João Paulo I que fica localizado na cidade de Canoas, região metropolitana de Porto Alegre. Participaram do projeto alunos que foram convidados pelos PIBIDianos, das turmas do oitavo e nono ano do ensino fundamental.

O referencial teórico adotado neste trabalho é o da Teoria de Mediação Cognitiva (TMC) (Souza; et al., 2012), que explana a cognição e o aprendizado por meio do processamento extra-cerebral, realizado em diferentes níveis de mediação. No nosso caso, as mediações presentes foram: psicofísica, por meio de atividades lúdicas; social, pelo contato com os tutores; cultural, por meio de livros; e finalmente hipercultural por meio do uso do Scratch e o jogo Angry Birds Space.

\section{METODOLOGIA}

Nossa metodologia consistiu de atividades inicias, para ajudar na construção do conhecimento dos alunos, o uso de um guia de atividades (descrito em anexo), um pós-teste - onde foi questionado aos estudantes sobre os diferentes tipos de movimento e sobre o que eles entendem por "gravidade" e "ângulo". Em seguida, realizamos uma entrevista com todos os participantes aqui descritos.

As atividades intermediárias, antes do pós-teste e entrevista consistiram de, inicialmente apresentar aos alunos o que seria abordado durante os encontros e comentamos sobre o software Scratch. Com auxílio de slides, explicamos sobre alguns conceitos/palavras da área de programação que poderiam aparecer no decorrer das aulas, como, 'computador', 'aplicativos', 'lógica', 'sequência', 'sequência lógica' e 'instruções'.

Mostramos o ambiente off-line de programação do Scratch (versão 1.4), como 'baixar 'e instalar nos computadores. Foi explicado cada comando do ambiente e, depois da familiarização dos alunos com o programa, solicitamos aos discentes aplicações simples, incluindo movimentos, orientações, comandos, a utilização do sempre (loop), sons, falas e trocas de objetos.

O jogo Angry Bird Space (Figura 1) tinha como incumbência dar um suporte necessário para os conceitos de lançamentos horizontal, vertical e oblíquo. Através deste jogo os alunos poderiam visualizar os conceitos fundamentados no Scratch e, posteriormente, realizar uma atividade de modelagem utilizando o software.

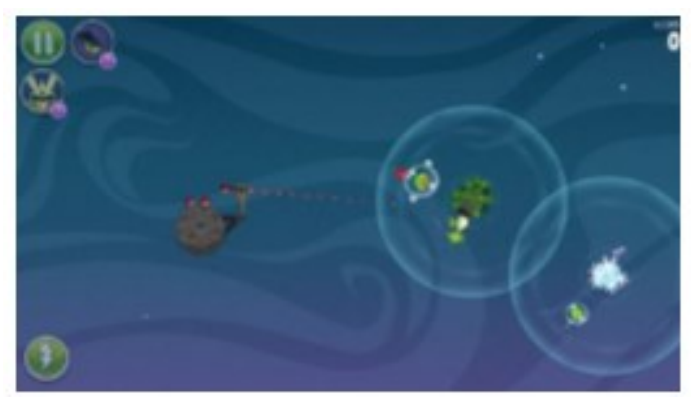

Fonte: Os autores (2016). 
Figura 2 - Alunos jogando o jogo Angry Birds Space

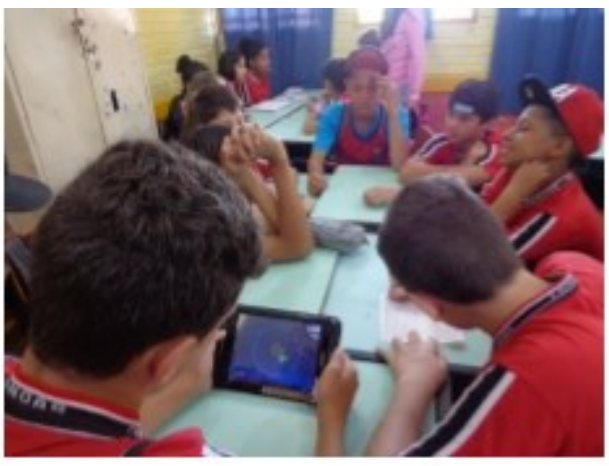

Fonte: Os autores (2016).

Após desenvolvidas as atividades envolvendo movimento horizontal e vertical, velocidade média e gravidade, os alunos construíram, juntamente com os PIBIDianos, um programa que simula o movimento oblíquo. Através dessa aplicação, pudemos explicar e exemplificar conceitos de ângulo, velocidade e trajetória.

Durante as aulas, foram criadas atividades lúdicas e brincadeiras, coma finalidade de demonstrar, fora do ambiente de programação, os conceitos ensinados. As atividades envolvidas foram, lançamento (arremesso) de objetos, exemplificando diferentes ângulos, cálculo de velocidade média (corrida) e brincadeiras onde os alunos deveriam atirar a bola falar qual o tipo de movimento.

Confeccionamos, para uma instrução mais detalhada de como utilizar o Scratch, um passo a passo (apêndice I) com a elaboração das atividades que simulam os conceitos dos tipos de movimentos trabalhados. O guia pode ser utilizado de forma independente pelos estudantes (especialmente aqueles que já tiveram contato com linguagem de programação). Caso seja necessário, poderá auxiliar o discente, ou quem tiver interesse, no momento de desenvolver e realizar as simulações das aplicações, mesmo que não tenha tanta familiaridade com o Scratch.

\section{RESULTADOS E DISCUSSÃO}

O projeto consistiu na criação de atividades computacionais abordando os conceitos de cinemática, como movimentos (horizontal, vertical e oblíquo), lançamentos de projéteis e ângulos, construídas pelos estudantes através do software Scratch, baseadas no jogo Angry Birds Space.

Também foram utilizadas, no decorrer do projeto, atividades lúdicas (Figura 3 ), onde os alunos participaram de brincadeiras, como lançamento de objetos (com intuito de acertar um alvo), corridas (trabalhando distância e tempo) e movimentos (horizontal, vertical e oblíquo), no qual demostravam as trajetórias e força da gravidade.

Figura 3 - Brincadeira "Vamos pular?" - Exemplificando a força da gravidade. 


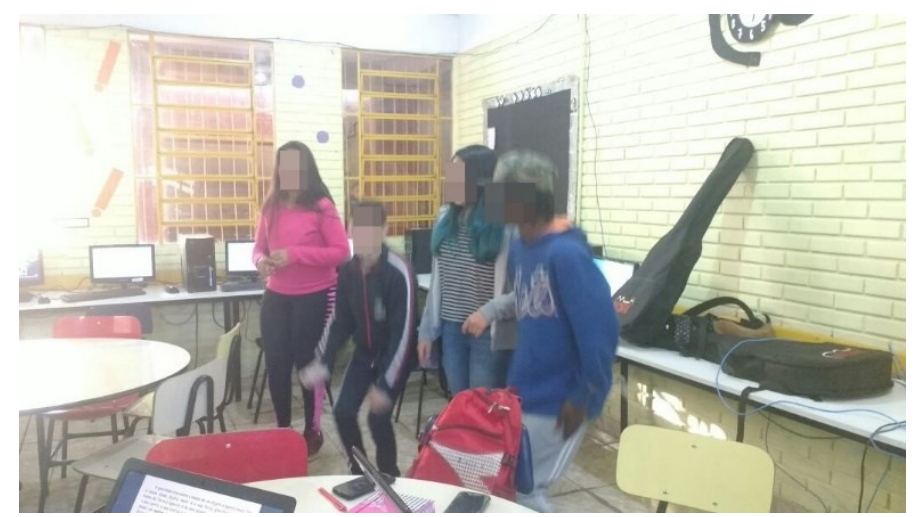

Fonte: Os autores (2016).

Durante os encontros os alunos foram estimulados a criarem alguns projetos, partindo da ideia de movimentos de corpos a serem representados ou modelados dentro da linguagem de programação. No início contávamos com 9 alunos, com faixa etárias entre 13 e 15 anos, os quais foram colocados para trabalhar em grupos ( 3 grupos de 3 alunos, cada), pois notamos que os estudantes tem a possibilidade de interagirem entre si e, dessa maneira, atuarem por vezes como "tutores mais capazes" (em um sentido Vygotskyano), uns dos outros quando colocados para trabalhar dessa forma.

Os grupos se mostraram interessados e motivados, já que, partindo do pressuposto, contávamos com duas novidades para eles - física e programação.

Ao longo das criações, anteriormente explicadas pelos docentes, os grupos foram se diferenciando. Para a análise, chamamos os grupos de GA, GB e GC.

O grupo GC se mostrava mais interessado no design do projeto do que nas atividades propostas, eram eles os que inventavam cores, sons e fundos diferentes. Apenas a utilização da ferramenta Scratch, não foi o suficiente para motivar o grupo a compreender os conceitos de física e programação. Já com atividades lúdicas, como lançamento de objetos e movimentos, fora do ambiente virtual, demonstraram conhecimento e interesse pelos assuntos trabalhados. Vale salientar que o grupo GC tinha pouca familiarização com computadores.

Já o grupo GB, desde o início, se mostrou dedicado a aprender tanto os conceitos físicos discutidos como a linguagem de programação. Não relacionavam a conhecimentos prévios, tanto de programação como de física, mas tinham um bom desempenho nas atividades propostas. O grupo buscava soluções para os problemas, pediam exemplos e conseguiam compreender, com alguma dificuldade em relação aos eixos cartesianos, os conceitos de cinemática. Faziam diversas perguntas referente a cinemática, aos conceitos de programação, questionavam sobre o software Scratch e funções do computador, como prints, copiar e colar e atalhos.

Ao contrário dos outros grupos, os alunos do grupo GA vinham se destacando desde a apresentação do projeto. Faziam perguntas mais elaboradas, aplicações diferenciadas e se superavam nas realizações de atividades dentro do software Scratch, nas aulas livres. Dos três alunos, dois já possuíam uma grande familiaridade com computação e facilidade para entender as funções do programa por terem um conhecimento prévio, já que participavam, virtualmente, de cursos sobre programação e outras linguagens. Sendo assim, eles conseguiam assimilar 
ideias com conceitos de física e movimentos planejados que trabalhamos e construir o que estava sendo solicitado, tendo, como todos, dificuldades no entendimento de alguns conceitos de cinemática.

De acordo com o nosso referencial teórico, o uso do Scratch proporciona o aprendizado de conceitos de lançamentos em física por meio de mediação hipercultural. Para demonstrar a aprendizagem e a eficiência do roteiro aplicado durante o projeto, segue abaixo um diálogo, relacionado ao lançamento oblíquo, onde através deste podemos notar o aprendizado do aluno referente ao conceito trabalhado (figura 4). Na análise, chamamos a aluna participante de A5 e o entrevistador de $\mathrm{E}$.

A5: Tem o oblíquo que é assim [03:08, \#MOB]...

E: Quando tu imagina o oblíquo, o que que tu está imaginando?

A5: Eu tô imaginando uma coisa assim [03:18, \#MOB].

\section{E: Que objeto?}

\section{A5: Olha, acho que eu imagino a bola de basquete.}

E: Interessante, e isso está no movimento, quando tu imagina o movimento oblíquo, tu imagina a gravidade nele?

A5: Sim, na hora que a bola cai.

\section{E: E quando ela está subindo?}

A5: Quando ela está subindo também, porquê tem que ter uma força para tocar ela pra cima né, então, em certo momento a gravidade, puxa ela, para, e daí cai [04:16, \#MOB].

Figura 4 - Nas imagens acima, a aluna realiza um movimento, da direita para esquerda, com o braço direito e a palma da mão voltada para baixo, em forma de arco (parábola), para frente e para baixo, demonstrando o movimento oblíquo. (\#MOB).

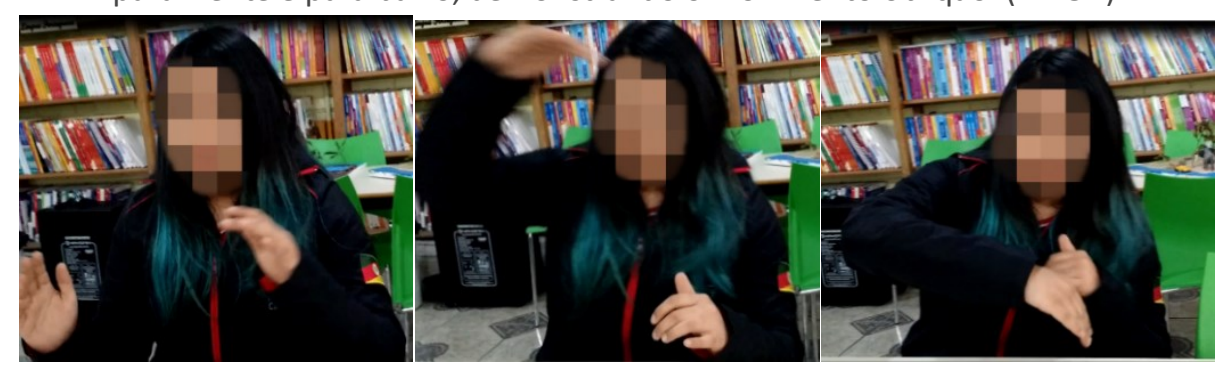

Fonte: Os autores (2016).

Os estudantes enfrentaram dificuldades para incluir as equações do movimento oblíquo na linguagem de programação Scratch. Então, pedimos para que apenas simulassem qualquer animação com lançamento e, depois, seria elaborado a aplicação de lançamento oblíquo.

Os grupos GC e GB realizaram as aplicações e lançamentos 'preliminares' no software. $O$ grupo GA se mostrou mais interessado em iniciar a atividade antes solicitada e não concluiu a atividade preliminar. Com ajuda dos docentes para a confecção da programação, a simulação foi concluída e, como planejado, pudemos utilizar o modelo como exemplo, também, para explicações de ângulos e trajetória. 
Apesar do grupo GA ter se destacado durante a programação, todos alunos prestaram atenção e tentaram concluir a atividade, seguindo o exemplo.

Contudo, naturalmente tivemos alguns percalços, no decorrer das aulas, alunos que se mostravam como destaques tiveram que abandonar as aulas, já que os encontros eram no contra turno e os mesmos começaram a trabalhar.

Outros demais alunos enfrentaram dificuldades de planejamento para a solução de problemas de cinemática, e, muitos, sem ao menos tentar ou mesmo tendo solucionado problemas anteriores semelhantes, não tiveram a iniciativa de buscar este conhecimento prévio teórico para solução de novos problemas e acabaram desistindo.

Levando em conta que são alunos do 8 e 9 ㅇ anos, sabemos que os mesmos podem ter dificuldade em assimilar com os assuntos trabalhados no projeto. Portanto, cabe ao professor integrar nas suas atividades a construção destes conceitos por mediação com os alunos, como tutor mais capaz.

Para manter a motivação dos estudantes, criamos mais algumas atividades fora do ambiente Scratch, mostrando conceitos práticos, como a gravidade, conceitos de velocidade média, diferentes ângulos e lançamentos. Além das atividades e simulações desenvolvidas pelo jogo.

Notamos que nas atividades virtuais seguintes, os alunos assimilavam bem os conceitos de lançamentos, movimentos e diferentes ângulos com o que havia sido trabalhado durante essas atividades lúdicas, demonstravam com explicações e manuseio de objetos. Na última situação-problema (Figura 5), que era a confecção de um programa (livre) sobre qualquer um dos conceitos abordados, os alunos obtiveram um bom resultado ao realizar o mesmo, demostrando corretamente os conceitos propostos no projeto, na programação do Scratch. Esta criação independente pode ser considerada uma transformação do conhecimento adquirido, que é evidencia de Aprendizagem Significativa Ausubeliana (AUSUBEL, 1978).

Figura 5 - Elaborado pelos alunos - Velocidade média

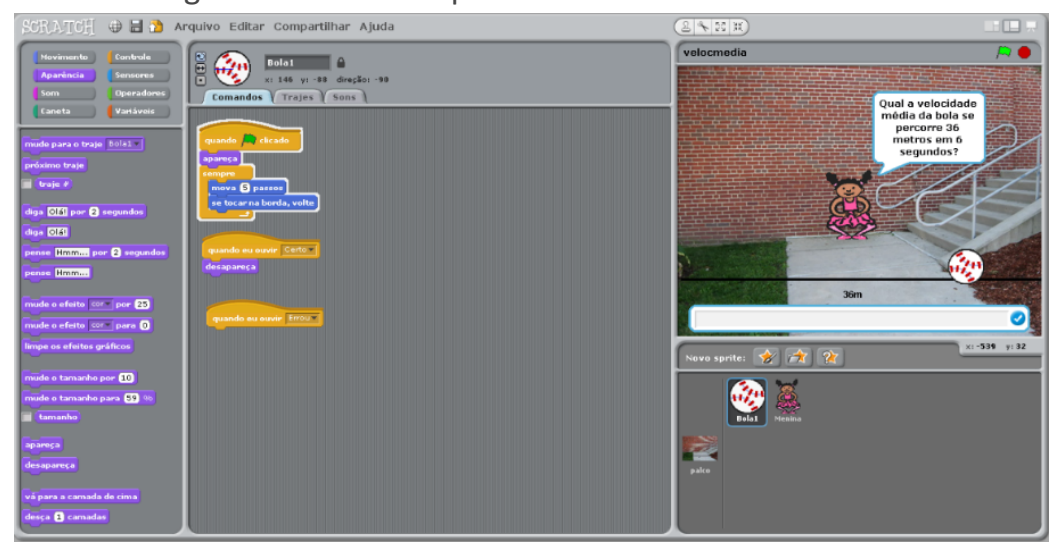

Fonte: Os autores (2016).

O uso do Scratch integrado com propostas de educação no ensino fundamental, tendo o jogo Angry Birds Space, a combinação das atividades torna o programa Scratch uma ferramenta computacional didática bastante poderosa. 0 software permite que o aluno interaja com um computador utilizando uma linguagem de programação que, após internalizada, torna-se uma ferramenta 
poderosa que permite-o desenvolver uma atividade de modelagem (ESQUEMBRE, 2001).

O Scratch, portanto, permite que o aluno modele um sistema Físico baseado nas suas concepções, vistas através do jogo Angry Birds Space que pode dar auxílio para aprendizagem de conceitos sejam elas científicas ou alternativas, e as teste.

\section{CONCLUSÕES}

Nos dias de hoje, é visível o interesse e a desenvoltura nos jogos eletrônicos por crianças e jovens. Consideramos que por este meio, devem-se estudar propostas para utilizar estes tipos de jogos/simulações em sala de aula, assim, aumentando o interesse e a curiosidade dos alunos pelas atividades que podem vir a ser propostas em conjunto com estas tecnologias de informações e comunicação.

A combinação entre o software Scratch e o Angry Birds Space, propiciou a associação dos movimentos que existem no jogo com o cotidiano e brincadeiras e também com linguagem de programação, que é modelado pelos estudantes com os mesmos movimentos. Com a análise dos resultados percebemos que o aprendizado de linguagem de programação, via Scratch, contribui não apenas numa melhor capacidade de encadeamento lógico de comandos, mas, também, como a programação visa modelar um fenômeno físico. Este aprendizado colabora com o ensino de conceitos físicos, em torno dos diferentes tipos de movimentos (horizontal, vertical e oblíquo) bem como gravidade.

As análises mostraram que a construção de jogos e/ou simulações através do Scratch proporciona um ambiente criativo, onde o educando mostra-se empenhado na busca de novos conhecimentos, tanto na área de Ciências, como na de tecnologia.

Desta forma, acreditamos, que o ensino de física deve efetivamente iniciar já nas séries iniciais, despertando o interesse pela busca científica para elucidar, e estimular a pesquisa e o aprofundamento cientifico ainda quando criança, não ficando tanto a mercê de suposições vagas e sem fundamentos científicos para que durante o ensino médio e eventualmente o ensino superior, o aprendizado de leis e conceitos físicos não seja visto como uma experiência negativa. E ao trabalhar com jogos eletrônicos e simulações computacionais, isto pode ser uma grande oportunidade para despertar a importância da ciência, na vida dos alunos e explorando a curiosidade dos alunos. 


\title{
Using scratch software for the learning of projectile motion and gravity concept in elementary school in Brazil
}

\begin{abstract}
The use of software and applications on mobiles has increasingly assisted in educational activities, in view of the rapid evolution of technological resources, and hence access to them. In this paper, we show how to use a combination of the Scratch software and the game Angry Birds Space for a learning / projectile launching education and the concept of gravity and, as a result, introduce programming in elementary school. As in Brazil, teaching physics is predominantly developed from high school physics learning the in elementary school, ends up abandoned and this work is an attempt to discuss activities that can be made in this level of education. The work was based on a PIBID project of Physics of the Lutheran University of Brazil.
\end{abstract}

KEYWORDS: Scratch. Angry Birds Space. physics teaching. PIBID. Kinematics. Gravity. Primary school. 


\section{REFERÊNCIAS}

AUSUBEL, D. P.; NOVAK, J. D.; HANESIAN, H. Educational Psychology: a cognitive veiw. 2a Ed. ed. New York, 1978.

RESNICK, M.; MALONEY J.; MONROYHERNÁNDEZ, A.; RUSK, N.; EASTMAN, E.; BRENNAN, K.; MILLNER, A.; ROSENBAUM, E.; SILVER, J.; SILVERMAN, B.; KAFAI, Y. Scratch: Programming for All. Communications of the ACM, v. 52, n. 11, p. 60-67. Nov. 2009.

SÁPIRAS, F. S.; VECCHIA, R. D.; MALTEMPI, M. V. Utilização do Scratch em sala de aula. Educação Matemática Pesquisa, PUC-SP, São Paulo, v.17, n.5, p. 973 - 988, 2015.

SCIENTIFIC AMERICAN. Education Is for the (Angry) Birds. Disponível em <http://www.scientificamerican.com/article/education-is-for-the-angry-birds/> Acesso em: 02 jun. 2014.

SOUZA, B.C.; SILVA, A.S.; SILVA, A.M.; ROAZZI, A.; SILVA CARRILHO, S.L. Putting the Cognitive Mediation Networks Theory to the test: Evaluation of a framework for understanding the digital age. Computers in Human Behavior, v. 28, n. 6, p. 2320-2330, 2012.

WHITE, B. Y.; FREDERIKSEN, J. R. Inquiry, Modeling, and metacognition: Making Science Accessible to All Students. Cognition and Instruction, v. 16, p. 3-118, 1998. 


\section{APÊNDICE I - Roteiro de aplicação da atividade didática com uso do Scratch para o ensino de cinemática em física}

1) Baixar o Ambiente Scratch (versão 1.4):

O programa está disponível em https://scratch.mit.edu;

Quando o Scratch 1.4 for aberto já estará no palco (Figura 6) um objeto, o Gato, o qual deverá ser excluído. Para isso clique com o botão direito do mouse e

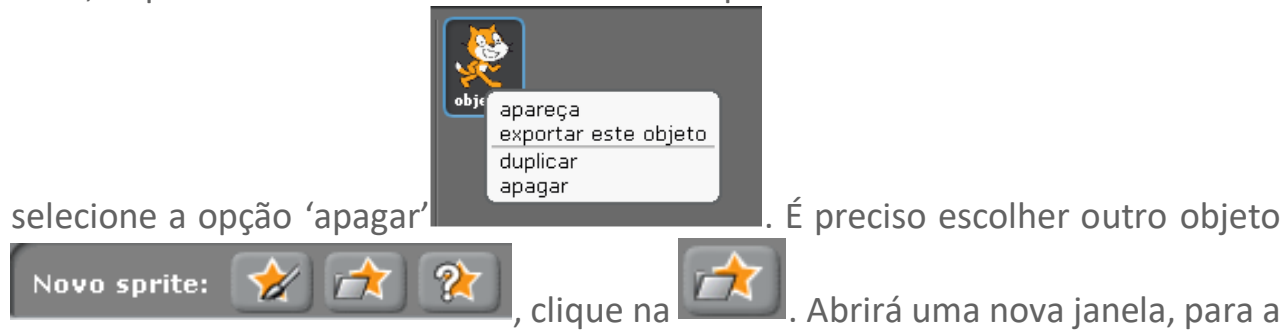
escolha dos objetos do programa, encontre uma bola e clique em ok. Ao pressionar ok o objeto aparecerá no palco. Para fins de simulação é necessário posicionar o objeto canto inferior esquerdo do palco e diminuir seu tamanho, clique em 米, o cursor do mouse aparecerá como na figura, clique, aproximadamente, 50 vezes sobre o objeto e o posicione como solicitado - no canto inferior esquerdo.

Figura 6-Ambiente Scratch

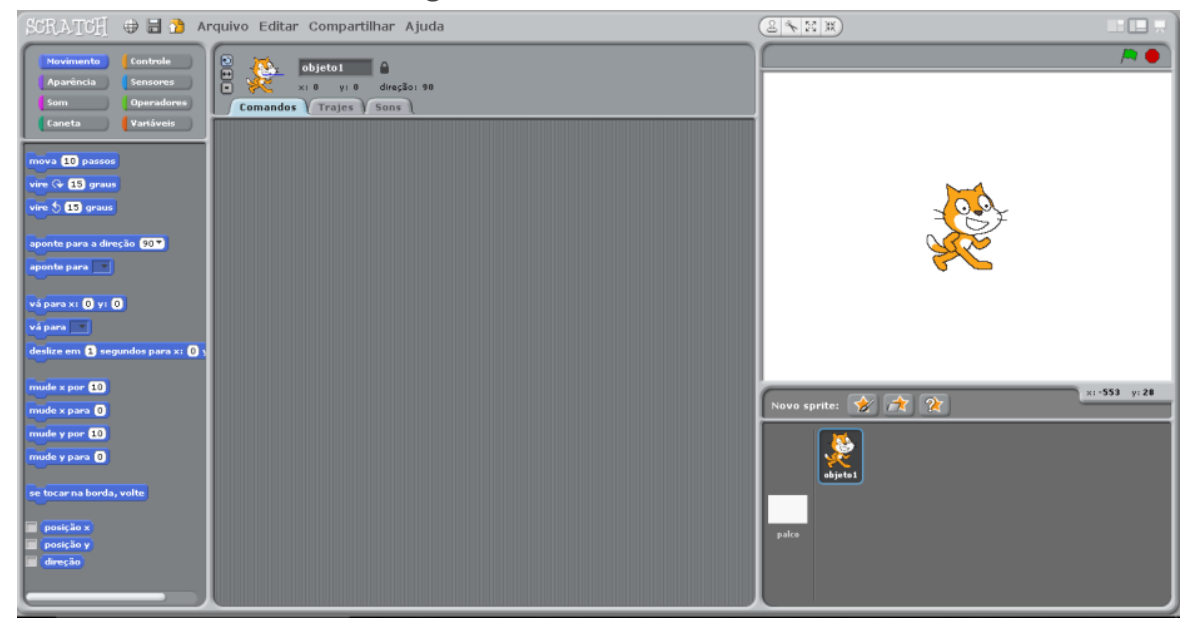

Fonte: Print screen do ambiente scratch (2016).

2) Sequência de comandos - palco:

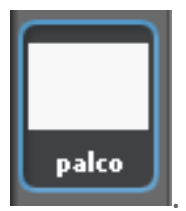

Com o mouse clique onde diz 'palco'

Primeiramente devemos (como mostra a figura 7) mover, ou arrastar um comando para a área de scripts. Para isso é só clicar em cima do objeto desejado, segurar e movê-lo para a área de Script, o espaço entre as colunas do ambiente. 


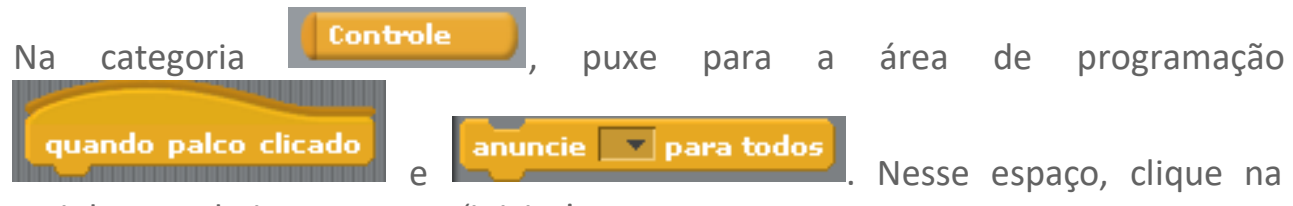

setinha para baixo e escreva 'iniciar'.

Figura 7 - Clique e arraste os blocos

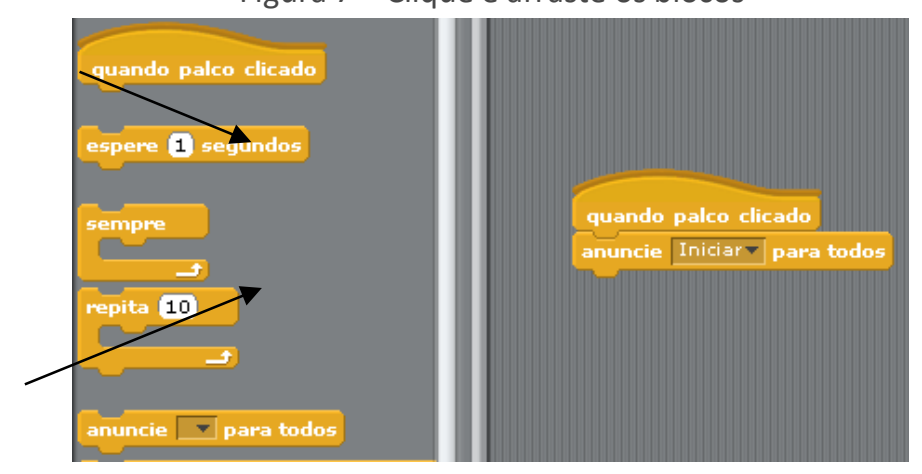

Fonte: Os autores (2016).

\section{3) Criar variáveis:}

Antes de elaborar os comandos do objeto, é necessário criar variáveis, elas serão utilizadas para, durante a simulação, fazer a troca de valores, simulando não só uma única situação.

Vá até o bloco Variáveis clique em criar uma Variável Abrirá uma aba para escrever o que estará simulando. Neste programa precisaremos de cinco variáveis, são elas: ângulo, tempo, $\mathrm{X}, \mathrm{Y}$ e velocidade. É preciso criar uma de cada

vez. Ao criar as variáveis, todas aparecerão como blocos

\begin{tabular}{|c|}
\hline criar uma Variável \\
\hline Apagar uma Variável \\
\hline$\checkmark$ TEMPO \\
\hline$\checkmark$ VELOCIDADE \\
\hline$\nabla \times$ \\
\hline$\nabla Y$ \\
\hline$\checkmark$ ÂNEULO \\
\hline
\end{tabular}

Quando criadas, as variáveis aparecem no palco. Para a simulação deixamos que as variáveis 'ângulo e velocidade' possam ser variadas manualmente justamente para as futuras explicações. Dê um duplo clique sobre elas no palco, agora ambas aparecerão com uma barra de rolagem, logo abaixo do nome -

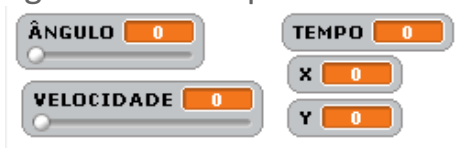

4) Sequência de comandos - objetos:

O palco e as variáveis estão prontas para atuar na simulação. Partimos agora

para a programação do objeto, clique em 


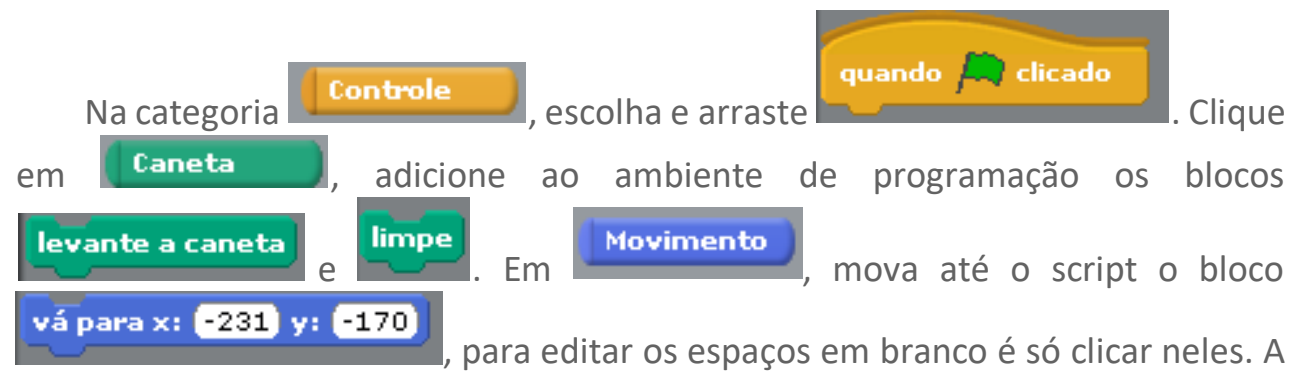

Figura 8 mostra como deve ficar essa etapa.

Figura 8 - Primeira etapa de programação do objeto

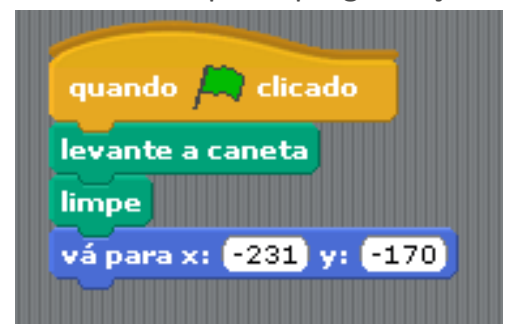

Fonte: Os autores (2016).

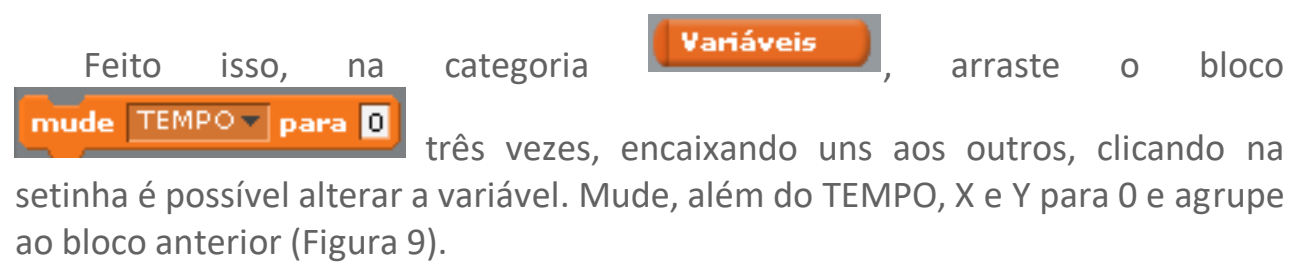

Figura 9 - Exemplo

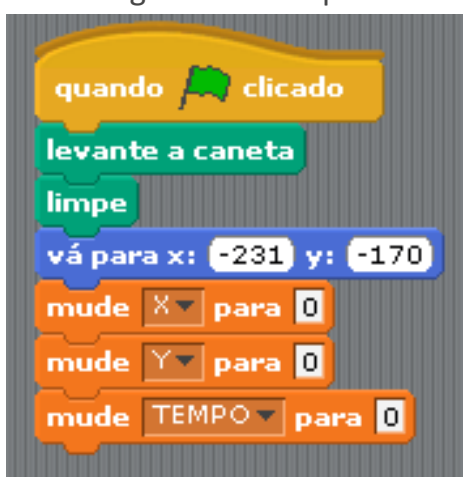

Fonte: Os autores (2016).

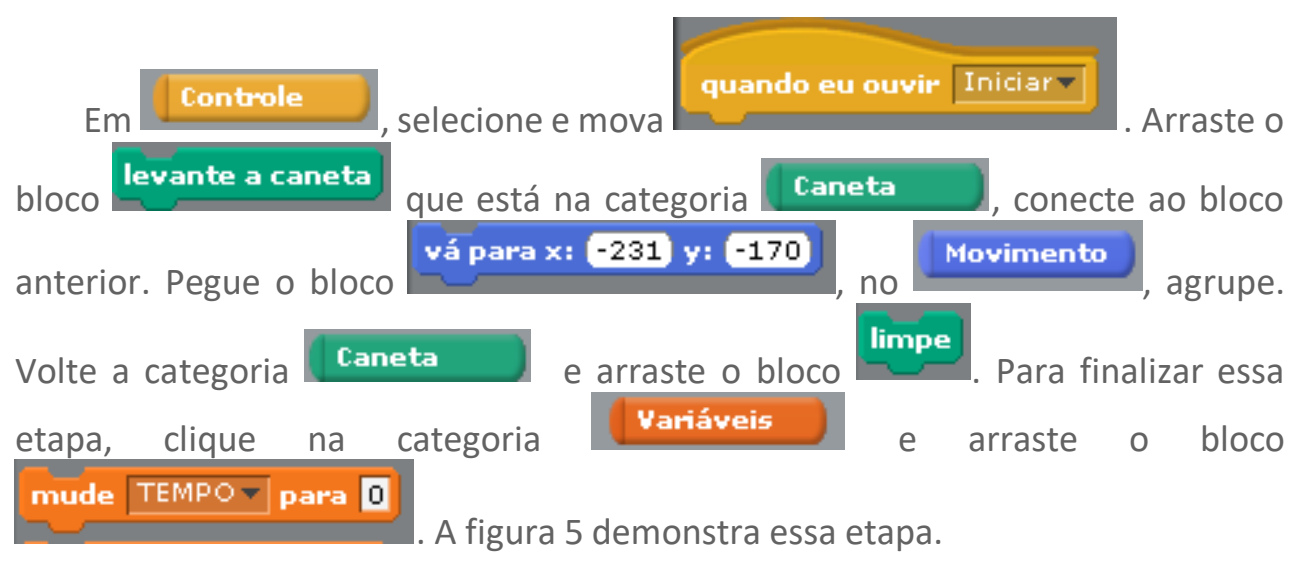


Figura 10 - Etapa relatada acima

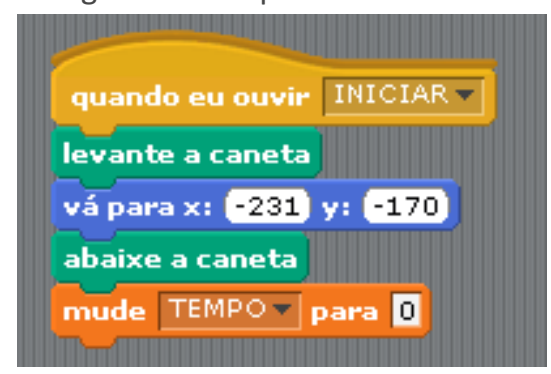

Fonte: Os autores (2016).

A sequência de programação do objeto, até agora (figura 11).

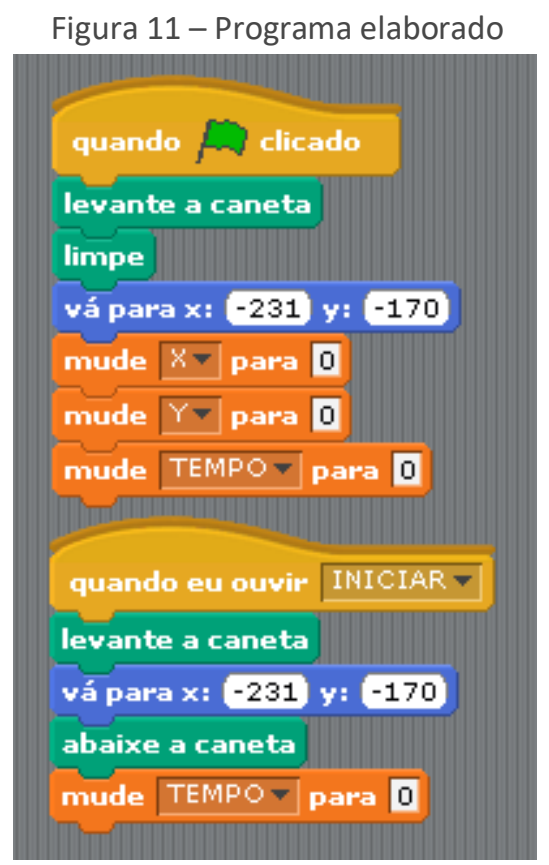

Fonte: Os autores (2016).

5.1) Utilização de comandos lógicos e operadores - agora todos os blocos serão agrupados dentro do bloco

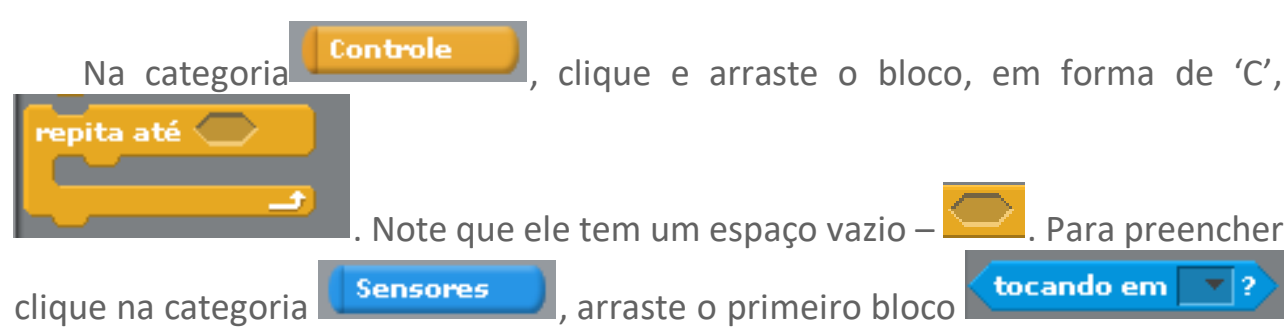
até o espaço, perceba que os blocos se encaixam. Clique na setinha ao lado do tocando em $\nabla$ ? 
Agora, será necessário incluir as equações referentes a $\mathrm{X}$ e $\mathrm{Y}$ no ambiente de programação, dentro do bloco

Equações para as aplicações de movimento horizontal $(X)$ e vertical $(Y)$ :

$$
\begin{gathered}
x=v_{0} t \\
y=v_{0} t-4,9 t^{2}
\end{gathered}
$$

Equações para a aplicação de movimento oblíquo:

$$
\begin{gathered}
x=v_{0} \cos \theta . t \\
y=v_{0} \sin \theta . t-4,9 t^{2}
\end{gathered}
$$

Para a construção das equações, utilize os blocos da categoria

Operadores As figuras 12, 13 e 14, movimentos horizontal, vertical e oblíquo, respectivamente, mostram os blocos (dessa última etapa), já agrupados, para cada tipo de movimento.

Figura 12 - Blocos - Movimento horizontal

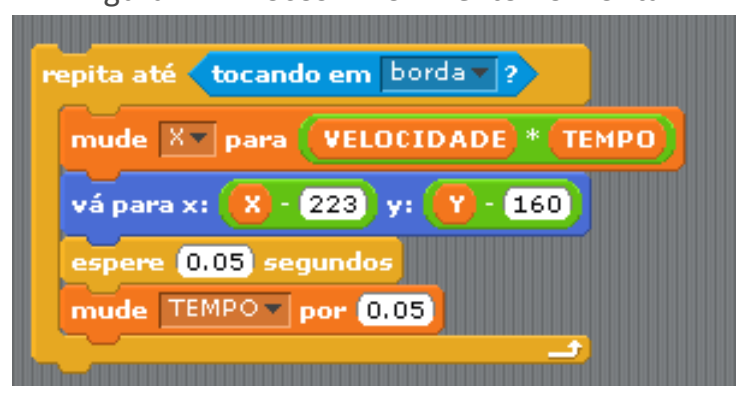

Fonte: Os autores (2016).

Figura 13 - Blocos - Movimento vertical

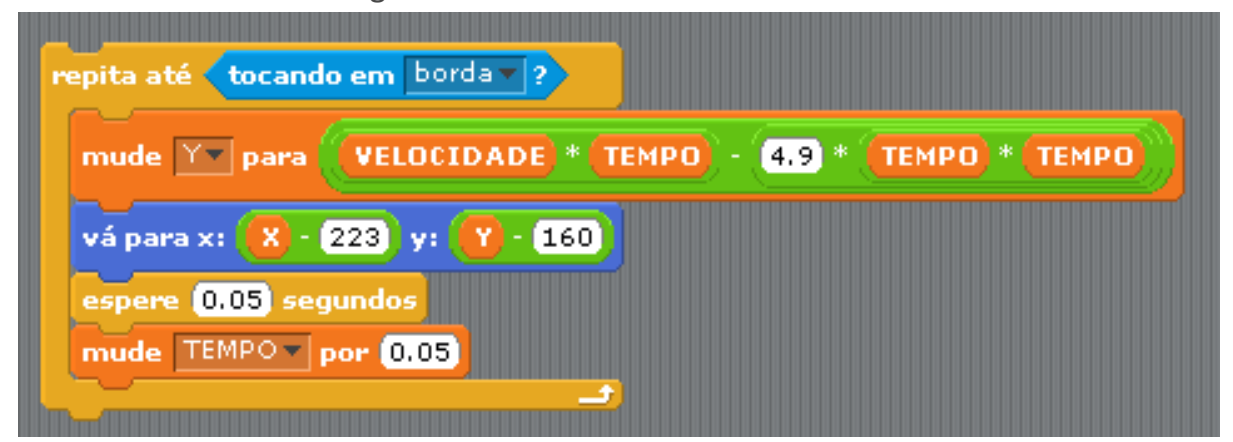

Fonte: Os autores (2016). 
Figura 14 - Blocos - Movimento Oblíquo

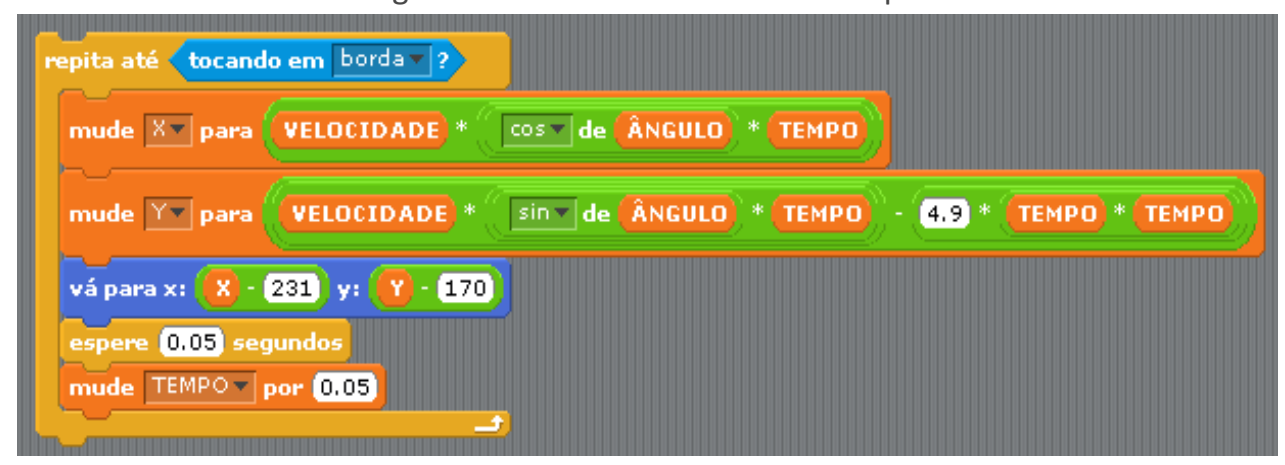

Fonte: Os autores (2016).

Na sequência temos as figuras 15, 16 e 17 que simulam animações (finais) referentes aos movimentos trabalhados. Possuem as mesmas instruções iniciais de programação, como visto nos passos anteriores, apenas no último bloco se diferenciam pelas equações.

Todas as três iniciam com uma bola no canto inferior esquerdo e, para iniciar a simulação é necessário clicar na e no palco.

Figura 15 - Movimento horizontal

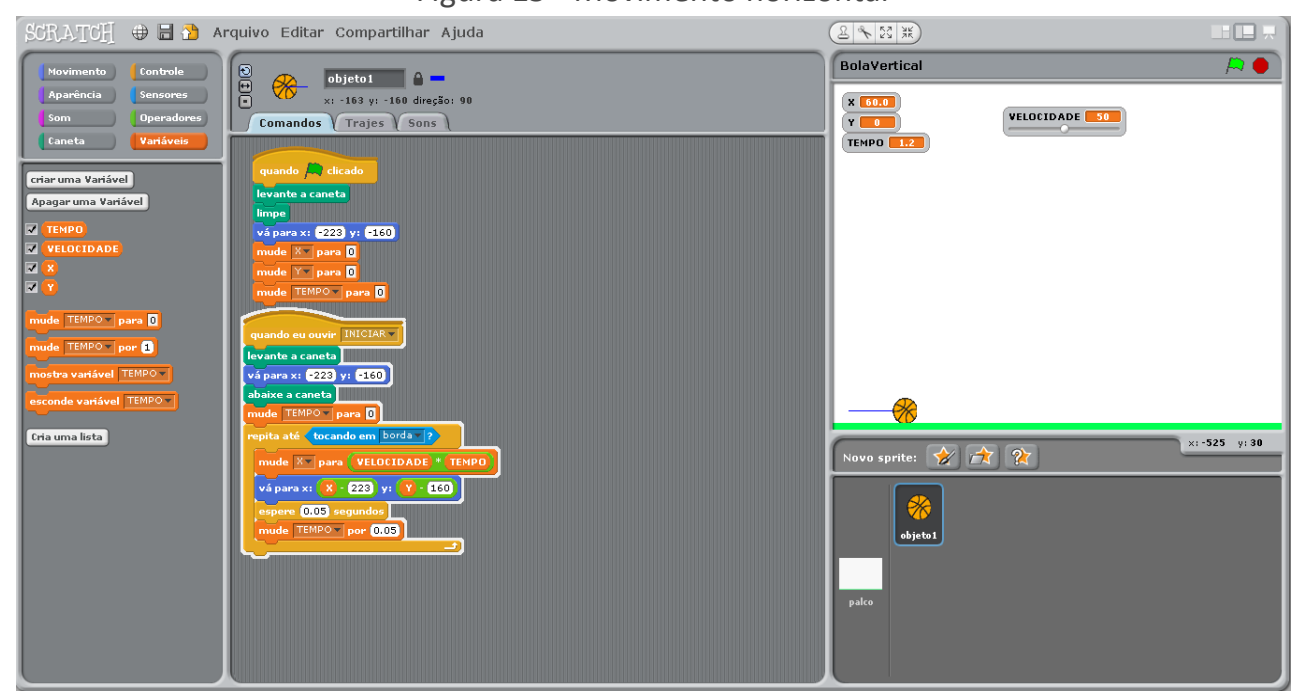

Fonte: Os autores (2016). 
Figura 16 - Movimento Vertical

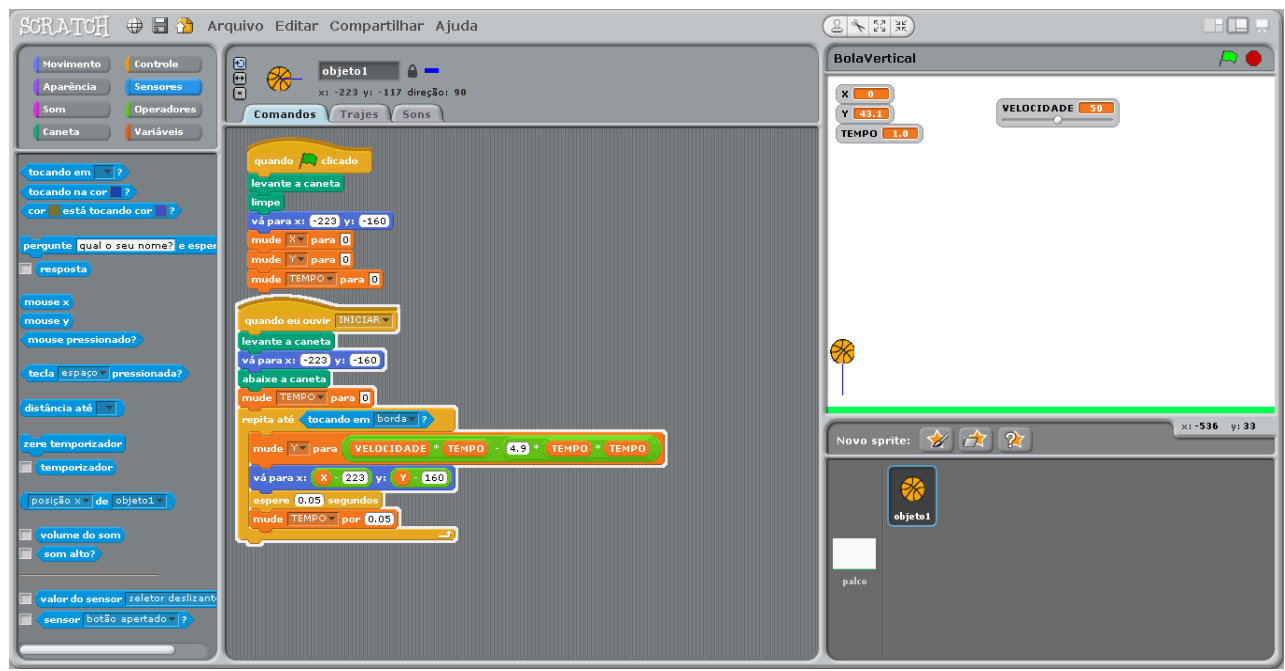

Fonte: Os autores (2016).

Figura 17 - Movimento Oblíquo

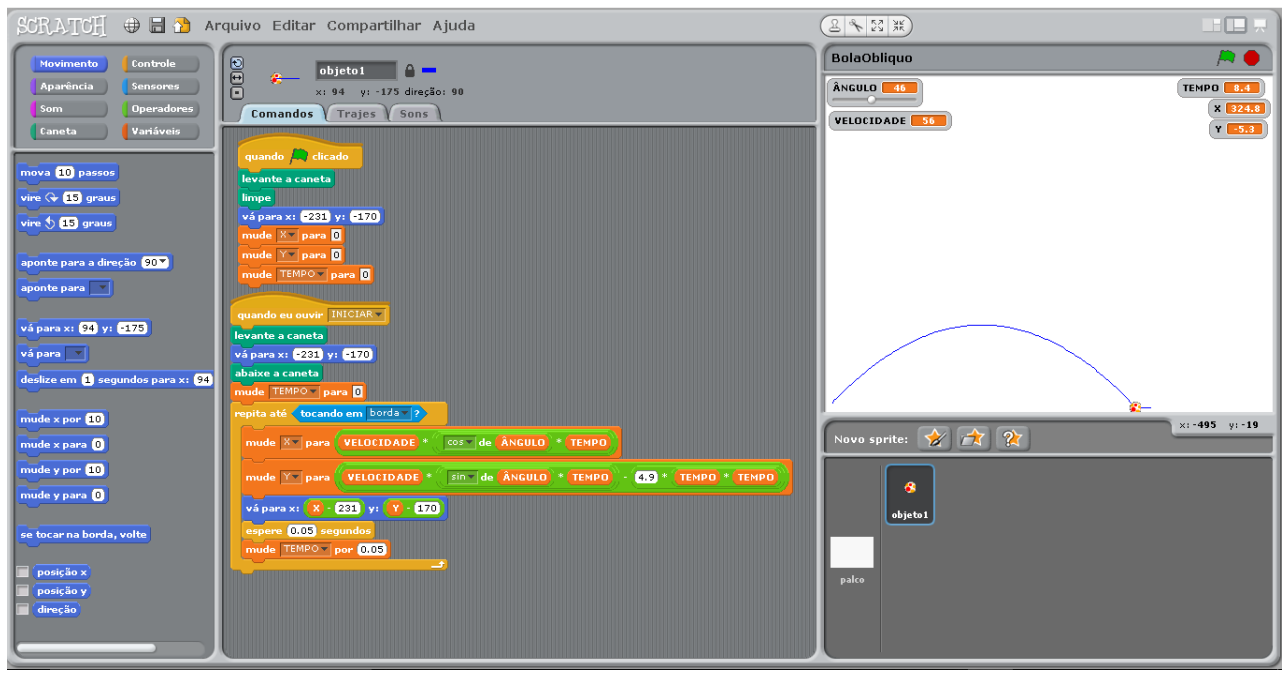

Fonte: Os autores (2016).

Recebido: 08 nov. 2016

Aprovado: 21 nov. 2016

DOI: $10.3895 /$ actio.v1n1.5004

Como citar:

ANJOS, J. R. dos; FREITAS, S. dos A.; ANDRADE NETO, A. S. de. Utilização do software scratch para a aprendizagem de lançamentos de projéteis e conceito de gravidade no ensino fundamental. ACTIO, Curitiba, v. 1, n. 1, p. 128-144, jul./dez. 2016. Disponível em: <https://periodicos.utfpr.edu.br/actio>. Acesso em: XXX. Correspondência:

Juliana Rodrigues dos Anjos

Rua Arquimedes, n. 05, Bairro Duque de Caxias, São Leopoldo, Rio Grande do Sul, Brasil.

Direito autoral: Este artigo está licenciado sob os termos da Licença Creative Commons-Atribuição 4.0

Internacional. 